\title{
The Impact of Teaching Academic Education Course of Children with Special Needs in the Ordinary Schools on Students' Attitudes toward Inclusion of Disabled Children
}

\author{
Abdelbaky Arafa Salem ${ }^{1}$ \\ ${ }^{1}$ Faculty of Education, Majmaah University, Saudi Arabia \\ Correspondence: Abdelbaky Arafa Salem, Department of Special Education, Faculty of Education, Majmaah \\ University, Saudi Arabia. Tel: 966-562-570-672. E-mail: a.salem@mu.edu.sa
}

Received: February 14, 2013

Accepted: March 2, 2013 Online Published: May 2, 2013

doi:10.5539/jel.v2n2p112

URL: http://dx.doi.org/10.5539/jel.v2n2p112

\begin{abstract}
The present study aimed at identifying the attitudes of the teacher student towards including students with special needs with the ordinary ones. Also, to determine whether there are statistically significant differences between students who have studied the academic education course of children with special needs in the ordinary schools and the students who have not studied this course in the Department of Special Education, Majmaah University for the academic year $1433-1432$ A H . The study concluded that there are statistically significant differences between the children of the fifth level who have studied the academic education course of children with special needs in the ordinary schools and the children of the fourth level who have not studied this academic course. Also, the study concluded that both of the students of Level IV and V have a positive attitudes towards inclusion of disabled students in the ordinary schools.
\end{abstract}

Keywords: attitudes, inclusion, children with special needs, students of department of special education

\section{Introduction}

The educational inclusion is considered one of the most modern programs in the education of disabled students, especially those with mild disabilities. The countries all over the world do its best to provide all the educational, social and healthy services suitable for students with special needs and that facilitate their inclusion in the society and education. The organizations and conferences with attention to the education and care for the disabled people called for their right to include into the society and this right is guaranteed by the Constitution.

In recent years, many countries all over the world move towards including disabled children with ordinary ones. Many educators not only ask for inclusion, but also support the comprehensive inclusion and the complete totality that means the education for all students, regardless of the degree of disability in the ordinary school. The schools should provide the supportive services.

To achieve the inclusion, it is necessary to prepare the community in all its classes to accept the social and educational inclusion for the disabled students. The importance of the direction as (Martin, Makelmen, 1974 ) and his colleagues say that the success of the process of inclusion mainly depend on the attitudes of teachers towards the inclusion, since the attitudes of teachers positively or negatively affect the achievement of the student and the behavior of both teacher and student (14).

Although this is such an important area, limited international studies have been carried out to understand pre-service teachers' concerns and preparedness for teaching diverse learners (see Forlin, Douglas, \& Hattie, 1996; Forlin, 2001; Forlin, Jobling, \& Carroll, 2001; Loreman, 002; Sharma, Ee, \& Desai, 2003, Umesh Sharma ,Chris Forlin ,Chris2006 ). Indeed, this was also highlighted by the Salamanca

Statement that emphasized a need for collaboration and networking amongst member nations in research and teaching on inclusive education. Research examining attitudes and similar constructs (e.g., concerns about implementing inclusion, and sentiments towards persons with disabilities) within an international framework may shed lights on role of factors that are context specific (example policy/legislative framework or cultural context). This may have useful implications both for teacher trainers as well as policy makers.

Hence the verification of the trends and feelings of the ordinary teachers and the teachers of special education 
towards the disabled students and towards accepting their inclusion in the ordinary classes is important. So, it provides one of the most important conditions of the success of inclusion programs.

As Zidan Alsartawi mentioned, it is necessary to verify the feelings of ordinary teachers and their attitudes towards disabled students. Also, it is necessary to work to acquire the necessary skills to work with them. In addition, prepare them to accept the differences between the students through the participation of teachers of special education in identifying the problem of the student and its causes, developing and implementing the appropriate program for disabled students in the ordinary class (Zidan Alsartawi, 2005).

\section{Study Problem}

It was noted, through research in the literature of special education, that the Attitudes towards inclusion has an importance cannot be ignored either in the success or failure of inclusion programs. So, the positive attitude towards inclusion of disabled students is one of the requirements of the success of inclusion i programs. Not only the positive Attitude of the teacher, but also the positive trend of the society in all its classes towards inclusion of disabled people is necessary to achieve the desired success and the aim of their inclusion. The teacher is the cornerstone in the process of education, especially in the care and upbringing of the disabled students. The student teacher represents the future for the teachers and the students of special education. The success or failure of inclusion programs in the near future will depend on their preparing and attitudes. When we desire to change the attitudes and convictions of the teacher, it should begin early in the process of formation, development and skills development. So the problem of this study arises and it could be formulated in the following question: What is the impact of the teaching of the students in the department of special education in the ordinary schools on their orientation towards the inclusion? This question leads to another one:

Are there statistically significant differences between scores averages of students who have studied this academic course and the students who have not studied this course in performance according to the measure of attitudes toward inclusion?

(Problem of the study lies in identifying the attitude of the students in the department of special education towards the inclusion of disabled students in the ordinary schools. Also, are there differences between the directions of students who have studied the academic education course of disabled students on changing their attitudes?)

\section{Research Importance}

It is known to most workers in the field of education and care of disabled students, especially those with mild disabilities that the programs of educational inclusion is one of the most modern and appropriate methods for their education in the ordinary schools. The recent researches and studies emphasize the importance of educational inclusion for disabled students. Also, the program of educational inclusion has been greatly supported as one of the programs of educating and teaching the students with special needs in Saudi Arabia.

This trend is confirmed as the number of disabled students enrolled in programs and institutes of special education in Saudi Arabia according to census 1428-1429 AH reached 2016 disabled student and represent 7\% of the number of disabled students. They are distributed in 29 Institute for Special Education and represents $1 \%$ of the programs and institutions of special education. They are distributed in 316 classes. The number of disabled students enrolled in special education programs, so-called partial inclusion programs, attached to the ordinary schools is 28,602 disabled students and represent $93 \%$ of the number of disabled students of 30,618 . They are distributed in 2067 program, equivalent to $98 \%$ of the programs, which number 2119 program. They are distributed in

4568 attached class of the total number of 4884 classes (Ministry of Education, Kingdom of Saudi Arabia, 1429. 1330).

The previous census confirms that Saudi Kingdom is interested in the programs of including the disabled students, whether the inclusion is partial for attached classes or some overall integration programs, which did not declare accurate statistics of their number. Through the expansion of the programs of inclusion, it must be interested in the trends of these programs' teachers and work to modify them towards positivism, because these trends have major impact on the success of inclusion programs.

So, this shows the importance of this study that deals with the impact of the academic education course for the disabled students in the ordinary schools. It is one of the courses of the fifth level, Department of Special Education. This academic course deals with the concept, objectives, and the benefits of inclusion, the factors of its success, the methods of its application and the obstacles facing inclusion programs, as well as dealing with the attitudes towards inclusion. So, this course plays an important role in identifying the students with the 
importance and objectives of inclusion programs. Hence, the impact of this course appears in modifying positively the trends of departments of special education programs towards the inclusion of disabled students according to the conditions and requirements that lead to success in its application.

1- The importance of this study, on one hand, is derived from the subject that it deals with and its importance in the success of inclusion programs and, on the other hand, of being a study characterized by renewal according to researchers' opinions, since it deals with the impact of education course of disabled students on modifying the attitudes of students toward inclusion.

2- The study, also, derives its importance in terms of their impact on modifying the trends of students towards the inclusion and its impact in the success of inclusion programs in the future.

3- The study, also, derived its importance in terms of its being an applied study deals with an educational one of the most important issues concerned with the education of disabled students in the educational field.

4- The study plays an important role cannot be ignored in the awareness of the community role towards the issues of disabilities.

\section{Research Aims}

The current research aims at:

The present study aims at identifying Attitudes of the student teacher towards integrating children with special needs with the ordinary ones. Also, to determine whether there are statistically significant differences between students who have studied the education course of disabled children in the ordinary schools and the students who have not studied this academic course?

\section{Methodology}

The present study used the descriptive analytical method in order to answer the questions of the study through the presentation and analysis of previous studies, as well as survey the views of Department of Special Education students who have studied the academic course of education for students with special needs and the students who have not studied this course.

The researcher will create a tool to take the views of the above categories to know the impact of teaching the course of education for students with special needs in changing the direction of the students of Department of Special Education to include the disabled students. The researcher will benefit from previous studies and literature of educational research to create the questionnaire

\subsection{The Current Research Uses Some Tools}

Including

1) An open- interview

2) A questionnaire

3) Seminars held with students

\subsection{Description of Study Tools}

The two researchers set up a questionnaire for the Attitudes toward inclusion. The questionnaire consists of (45 phrases) measure the direction of the students of Department of Special Education, either the students who studied the academic education course of the children with special needs or the students who did not study this course towards the inclusion of the students with mild special needs with the ordinary ones.

\subsection{Study Procedures}

The study was conducted in accordance with the following steps

1) The researcher makes certain of stability and validity of the measure.

2) Determining the sample number.

3) Distributing the measures to the sample number.

4) Collecting and entering the measures into the computer, then processing them statically by the statistical program for social science (SPSS).

\subsection{Study Limitations 1}

The study confined to students of Department of Special Education at Majmaah University, the students of sixth grade who have studied the academic education course of students with special needs in the ordinary schools and 
the students of the fourth level who have not studied this course.

1-The study had been applied in the second semester of the academic year 1432-1433 AH. The number of students who were applied by the questionnaire and were interviewed, workshops and other tools of the study was 40 students who completed the study of academic education course for children with special needs in the ordinary schools. They are students of Level VI of different specializations (mental retardation, learning disabilities and autism), where that course was taught to students of the fifth level and other 40 students from the fourth level did not study the education course for the children with special needs in the ordinary schools and did not specialize .

2-The results of the study are determined according to the responses of the sample towards the used tool.

\subsection{Study Terminology}

\section{1- Attitudes}

It means in this study a set of student responses towards different situations included in the questionnaire. The total scores for the student express the degree of student's direction towards inclusion, so that the high degree refers to the positivism of this trend, while low degree refers to the negativism of this trend.

\section{2- Inclusion}

It means in this study teaching the students with mild disabilities from different groups of disabled students in the ordinary schools, either partial inclusion for some time or total inclusion for all time.

\section{3- Children with special needs}

In 1973, UNESCO defined children with special needs as "children who are different from their ordinary colleagues in their mental, sensory, emotional, and motor development, which requires educators' special attention in terms of: methods of their diagnosis, the number of educational programs and their own methods of teaching". This definition includes all disabilities in need to methods of teaching, curricula, teachers, and educators have the abilities to deal with these disabilities including the mental, sensory, emotional and motor disability. These disabilities were classified in this way to determine the needs of each disability and the best way to deal with.

\section{4- Students of Department of Special Education}

They are students of the Department of Special Education, Faculty of Administrative Sciences and Humanities at Majmaah University, which was established in 1429 and was affiliated to the University of King Saud.

And then became affiliated to Majmaah University in 1430, beginning with the fifth level and also the students who have completed the academic course of students with special needs in the ordinary schools as well as the students of the fourth level who have not studied this course.

\section{Previous Studies}

1- Study of Mohammed Abdul Twab Abu Nour (2008) aimed at identifying the impact of the program of preparing teacher of special education (diploma of private vocational education) on the attitudes of teachers towards the inclusion of students with special needs in the ordinary schools. The sample consisted of 117 questionnaires were distributed to 48 teachers from graduates of Diploma of Special Education, 69 teachers from non-graduates of diploma of special vocational education. The study showed statistically significant differences in scores averages of teachers in favor of the teachers who obtained a diploma in special education.

2- Study of Larfy (1981), which showed that the specialized knowledge and information in addition to effective training have an effect in changing attitudes towards educating and teaching the disabled children in the ordinary schools, where the researcher worked with 941 teachers for one year, and found that $95 \%$ of teachers who have received specialized information and effective training see it is necessary to provide the opportunity for disabled students to learn in less restrictive environments.

3- Study of Mac Dougal (2004) which aimed at identifying the impact of school culture on the attitudes of ordinary students toward their disabled peers. The sample consisted of 1872 students from the normal students. The results showed That about $61 \%$ of the students have attitudes ranging from neutral to very positive, and about $21 \%$ of students have trends ranging from less than neutral to very negative trends.

4- Study of Aladdin Kafafi (2004): A study entitled "attitudes towards the experience of inclusion children with special needs with normal children at the primary schools."

The study aimed at identifying the attitudes of education officials, parents of normal children, disabled children, 
normal children and disabled children towards the experience of including children with special needs in Egypt.

The study used the referendums for each category (education officials, parents of normal children, parents of children with special needs, normal children and children with special needs).

The results of the study for education officials showed that more than $53 \%$ support the experience of education ministry in establishing classrooms of inclusion.

$5 \%$ of the education officials announced their support for inclusion in activities at the moment while $7 \%$ of the officials support the complete inclusion.

$66 \%$ of the education officials support that the teacher preparation course of this experience is via training programs or through preparing in university programs. One of the positive aspects of experience as seen by the officials of education in favor of children with special needs is the good behaviors. One of the most negative aspects as seen by education officials is the lack of teachers and equipment.

\section{For parents of normal children:}

$37 \%$ of parents of normal children see that there are problems can occur to their children in the case of inclusion, while $63 \%$ of them acknowledged that there is no problem. $71 \%$ of the parents of normal children see that the child with special needs benefits from his presence with the normal child in general. $52 \%$ of parents of normal children agreed upon the existence of children with special needs with their children and the rest opposed that.

\section{For parents of disabled children:}

$84 \%$ of parents of disabled children agreed upon the presence of their children in an ordinary school because it teaches them better habits of behavior. $76 \%$ of parents of disabled children approved that their children benefit from this system. $66 \%$ of them said that the presence of their children with normal ones does not cause any problems.

\section{For normal children:}

$81 \%$ of normal children welcomed the presence of disabled ones. $68 \%$ of them prefer the inclusion in activities $.30 \%$ of them support the full inclusion and $87 \%$ of them acknowledged that the children with special needs are good at first. $74 \%$ of them admitted that they understand them by signs, and $68 \%$ of them acknowledged that they are happy in the presence of these children with them.

\section{For disabled children:}

$95 \%$ of the disabled children love the school in which they study and do not want to transfer to schools of intellectual education. $41 \%$ of them acknowledge that there are differences between them and the normal children. $80 \%$ of them acknowledge that they love the children of their classroom more than the normal children. $54 \%$ of them want to interact with normal children in order not to feel that they are less than them.

Some proposals of the study: Teacher preparation, experiment following - up and aware parents and the entire community. The current study benefited from this study to know the trends of those responsible officials for the experience of including children with special needs, the trends of teachers towards the inclusion, knowing the direction of parents, either normal or with special needs towards inclusion and the opinion of normal and disabled students about inclusion programs. Also, the study benefited to know some of the obstacles facing the project, such as the lack of capabilities, equipment and the teachers required for the project success.

5- Study of Abdul-Aziz Abdul Jabbar (1999): Abdul jabbar conducted another study on a representative sample consisted of (510) of managers and teachers work in ordinary primary schools affiliated to the educational Riyadh governorate, Ministry of Education. The results has shown opposition to include the categories of children who suffer from cerebral palsy, deaf, blind and mentally retarded, while the sample number agreed upon including the other cases, such as children categories of diabetes, physical disabilities, impaired seeing, impaired hearing and behaviorally disturbed and those who suffer from stuttering, who difficult to understand their words and who suffer from epilepsy.

6- Study of Farid Mustafa al-Khatib (2004): This study aimed at identifying the directions of working staff in the primary schools that have applied the program of including the children with simple mental disability. The sample of the study included all the schools applied for the program of inclusion. It includes 10 schools and 96 teachers and employees. The study found that there was no effect of statistical significance for the variables of gender and experience on the attitudes of staff working in the program to include the students with mental disabilities in the ordinary schools, while the results showed differences of statistical significance due to the variable of the age in favour of the students less than 25 years. 
7- Study of Umesh Sharma and others (2006) at Monash University: The study aimed to investigate the effect of training pre-service teachers in Australia, Canada, Hong Kong and Singapore to acquire the concepts and modify the positive trends towards inclusion. The study found that there are differences between the East countries: Singapore and Hong Kong and the West countries: Canada and Australia in favour of the West countries: Canada and Australia, where positive trends are rising towards inclusion of disabled children and get the different concepts of inclusion for the teachers in Western countries into the Eastern countries. The study suggested increasing the programs of teachers' training in the Eastern countries to increase the positive trend towards including the disabled students and increase acquiring the different concepts of inclusion.

8- Study of Efrosini Kalyva, Dina Gojkovic (2007): This study investigated the attitudes of 72 Serbian teachers towards the inclusion of children with Special Educational Needs (SEN) in mainstream schools; they were asked to complete My Thinking About Inclusion Questionnaire (Stoiber, Goettinger, \& Goetz, 1998). It was found that Serbian teachers held overall slightly negative attitudes towards the inclusion of children with SEN, with teachers with experience in teaching children with SEN holding more positive attitudes towards inclusion in comparison to teachers without such experience. No differences were observed in teachers' attitudes towards inclusion according to their years of teaching experience. Findings are discussed in relation to the effectiveness of changes that were implemented recently in Serbia regarding the educational rights and needs of children with SEN.

9- STUDY OF Zarife Seçer (2010) Faculty of Vocational Education, Selcuk University, Konya, Turkey: The aim of this article is to examine differences between the attitudes of preschool teachers before and after an INSET course. Sixty-six preschool teachers were selected for this study which had a single group pre-post-test design. The teachers' opinions and attitudes relating to mainstreaming SEN students in regular educational environments were assessed using the 'Opinions Relative to Mainstreaming' scale. The data indicate that these teachers were affected by the INSET programme in such a way that their attitudes towards the inclusion of SEN students became more positive.

10- STUDY OF Olli-Pekka Malinen, Hannu Savolainen (2008). University of Jyväskylä and University of Joensuu: Sample of 523 Chinese university students was given a questionnaire on their attitudes towards the inclusion of children with disabilities into regular classrooms. Factor analysis, analysis of variance, t-test and correlations were used to assess the respondents' general attitude towards inclusion, the factor structure of the attitudes, the relationship between demographic variables and the attitudes and the ratings of best educational environments for students with different kinds of disabilities. The analysis revealed that (a) the participants' average attitude towards inclusion was slightly negative; (b) four factors, named as Social justice, Meeting the special needs of the pupils with severe disabilities, Quality of education and Teachers' competence, were extracted (c) the most important background variable that explained the attitudes was the participants' major subject in the University; and (d) the ratings for the best educational environment for a student with a disability varied according to different types and levels of disability.

11- study of Steven Elliott(2008), University of North Carolina at Wilmington: The purpose of this study was to ascertain the relationship between teachers' attitudes toward the inclusion of children with mild to moderate mental disabilities in physical education settings and the amount of practice attempts performed and the levels of success attained by these students compared to their peers without disabilities. The findings suggested a relationship between teacher attitude toward inclusion and teacher effectiveness. Teachers with a positive attitude toward inclusion provided all of their students with significantly more practice attempts, at a higher level of success.

12- Study of Doulkeridou A, Doulkeridou A, Evaggelinou Aristotle(2011) University of Thessaloniki, Greece: The purpose of this study was to examine the attitudes of Physical Educators toward the inclusion of students with disabilities and SEN in general Physical Education (PE) classes and to compare them with those teachers who taught the course of Olympic/Paralympic Education $(\mathrm{O} / \mathrm{PE})$ as well as examine gender differences. Four hundred and ten PE teachers (200 male and 210 female) of an average age of 33.58 years from different prefectures of Greece completed a modified version of the questionnaire Attitudes toward Teaching Individuals with Physical Disabilities in Physical Education (ATIPDPE) of Kudlacek et al (2002). Two-way ANOVA was used to analyze the data. The results revealed positive attitudes of all teachers toward teaching students with disabilities and SEN in PE classes; however, there were no significant differences between those who taught different type of PE courses as well as between males and females. It is strongly suggested an ongoing assessment should examine the changes in education of students with disabilities and SEN and their inclusion in the general schools and how. 
13- Study of Andile Mdikann,Sibusiso Ntshangase (2007) University of the Witwatersrand: The inclusion of learners with special educational needs in general education is becoming more prevalent. As a result various special education researchers have begun to examine the success of inclusion, as well as the attitudes and beliefs of general educators towards the inclusion of learners with disabilities in the general education classroom. In the present study, preservice educators' attitudes towards inclusive education were investigated. The participants are full time students of the University of the Witwatersrand in Johannesburg. These students are registered for the Post Graduate Certificate in Education, B.Phys.ed) and B.A (Ed) and they are all in their final year of study. The students are mainly English-speaking. The sample comprises of 22 students seven males and fifteen females. Convenient sampling design was employed. A questionnaire developed by Choles (1997) was adapted and was used as a measuring instrument to record the responses of the research respondents. The adapted questionnaire comprised of the following sections: Biographical details, Attitudes towards inclusive education, Requirements for competency, Requirements for successful inclusion and Attitudes towards learners with Special Needs. Data were analyzed using descriptive statistics. The research participants were generally found to have positive attitudes toward inclusive education. The results of this investigation are significant in the sense that the understanding of pre-service educators' attitudes is critical for the successful implementation of inclusive education (Mowes, 2000; Elloker, 1999; Gadium, 2002; Dover, 2002; \& Mckeskey \& Waldrom, 2002).

14- Study of Khochen, Maha; Radford, Julie (2012): This study explores the attitudes of teachers and headteachers towards people with a disability in mainstream primary schools in Lebanon, a middle-income Arab country. A mixed method approach was used to collect data. Forty teachers from mainstream schools within the Project completed questionnaires, and key headteachers as well as the consortium managers were interviewed. The sample was purposively selected in order to examine the attitudes of participants with previous experience of students with disabilities. In general, the findings indicate positive attitudes towards the inclusion of students in mainstream schools. However, participants expressed reservations about including all students, especially those with social, emotional and behavioural difficulties. Further challenges include limited training, availability of qualified specialist teachers and the high cost of supporting inclusion. These findings will inform future research, as more studies regarding the implementation of inclusive education in the Middle East are warranted.

\subsection{Comments on the Previous Studies}

Through a review of the previous studies that are related to the subject of the current study and largely benefited the researcher, the current study is different since it deals with the impact of teaching the academic education course of disabled children in the ordinary schools on the students of the Department of Special Education; the subject has never been previously studied. Some studies dealt with the impact of the Study in Diploma of Special Education on modifying the attitudes of students towards the inclusion.

The clear difference is that this study deals with the impact of teaching the course which discusses, in a clear, explicit and intensive form, the issues of including the disabled children in the ordinary schools from all different aspects, since this course deals with the concepts and terms related to inclusion and addresses the trends and tendencies and their historical development toward programs of inclusion. Also, it deals with the ways of changing the attitudes and community awareness of the importance, the benefits and positive aspects of inclusion for the normal child, the disabled child, the family, the teachers and the society as a whole. Also, it deals with the factors of success of inclusion programs and the experiences of Arab and foreign countries towards inclusion programs. The course also deals with the roles of the normal teacher and the teacher of the special education in inclusion programs and the most important skills that they must be enjoyed to do their roles in inclusion programs. Some studies have dealt with the trend towards inclusion in many countries of the world. The studies found a significant modification in the directions of teachers and workers in education as well as the most segments of society towards disability issues in general and towards the issues of inclusion specifically of the negative trend on positive one. This has been clearly shown in the previous studies such as the study of Abdul Ghafoor, Abdul Jabbar, Ala, and other studie.

\section{Study Field}

Following the researcher's ending from creating the study tools which consists of:

1- Open interviews: with a number of students in special education department who has studied the academic course for children with special needs and those who did not study this course.

\subsection{The Questionnaire}

The researcher created the questionnaire and depended on the literature of special education and previous studies in the research field to form it. The final questionnaire consists of (45) phrases following an arbitration by 
specialists in the field of special education and some other specializations in the field of education, omitting and modifying some phrases.

\subsection{Questionnaire Validity}

The research depended on (the validity of the arbitrators). The primary questionnaire has been introduced to (8) specialist professors in the education field to test the validity of the questionnaire contents. The arbitrators are asked to give their points of view in the range of agreement between the items of the questionnaire and its purposes, the clearness of its language. Also, they are asked to modify, add, omit if necessary. According to arbitrators' views, the questionnaire came in its final shape following making the proposed modifications such as omitting some paragraphs and modifying others. The final number of paragraphs is shown in the table.

\subsection{Questionnaire Stability}

The researcher depended on the program of statistical analysis (SPSS) to achieve the stability of the questionnaire. The researcher entered the data of questionnaires. Through the program, the researcher reached a high rate of stability of $92 \%$ could be depended upon it.

\section{The Study Results}

Before the study begins in analyzing the results of the study, it is important to emphasize that the programs of teacher training based on competencies aim at learner's reaching at a predetermined level cannot be graduated without it. One of the concerns of these major programs is raising the efficiency of the learners to the highest possible levels. Lawrence Peter says the efficiency of the teacher is not measured through the courses of students teachers, the total hours they completed, the time spent in training or any other requirements for graduation, but it should be determined by the impact of teacher performance in learning the students. Through this study, the impact of training is clear in the dialogue, the persuasion and modifying the trends through workshops, sessions, seminars, presentations and videos that were displayed to modify and change the negative attitudes of students toward inclusion programs for the students of the fifth level who study the academic education course of children with special needs in the ordinary schools.

Following the researcher applying the questionnaire on the study sample, which was as follows:

80 students from the Department of Special Education students who have studied the academic education course of children with special needs and those who have not studied this course.

\subsection{Questionnaire Validity}

The research depended on (the validity of the arbitrators). The primary questionnaire has been introduced to (8) specialist professors in the education field to test the validity of the questionnaire contents. The arbitrators are asked to give their points of view in the range of agreement between the items of the questionnaire and its purposes, the clearness of its language. Also, they are asked to modify, add, omit if necessary. According to arbitrators' views, the questionnaire came in its final shape following making the proposed modifications such as omitting some paragraphs and modifying others. The final number of paragraphs is shown in the table.

\subsection{Questionnaire Stability}

The researcher depended on the program of statistical analysis (SPSS) to achieve the stability of the questionnaire. The researcher entered the data of questionnaires. Through the program, the researcher reached a high rate of stability of $92 \%$ could be depended upon it.

\section{The Study Results}

Before the study begins in analyzing the results of the study, it is important to emphasize that the programs of teacher training based on competencies aim at learner's reaching at a predetermined level cannot be graduated without it. One of the concerns of these major programs is raising the efficiency of the learners to the highest possible levels. Lawrence Peter says the efficiency of the teacher is not measured through the courses of students teachers, the total hours they completed, the time spent in training or any other requirements for graduation, but it should be determined by the impact of teacher performance in learning the students. Through this study, the impact of training is clear in the dialogue, the persuasion and modifying the trends through workshops, sessions, seminars, presentations and videos that were displayed to modify and change the negative attitudes of students toward inclusion programs for the students of the fifth level who study the academic education course of children with special needs in the ordinary schools.

Following the researcher applying the questionnaire on the study sample, which was as follows:

80 students from the Department of Special Education students who have studied the academic education course 
of children with special needs and those who have not studied this course.

\subsection{Statistical Methods}

The researcher used the program of statistical analysis ( spss) to reach the frequency and percentages to determine the degree of importance of each phrase in the questionnaire towards every member of the sample before and after the implementation of the program.

\subsection{Results and Analysis}

The study aimed at identifying the effect of teaching the academic education course of children with special needs in the ordinary schools on changing the attitudes of students towards the inclusion of disabled children with normal ones. The study found that there are differences of statistical significance between the two samples numbers in favour of the sixth grade students who have studied the academic course. The study agrees with the study of Abu Nour (2004) in the existence of statistically significant differences towards disability issues among the students in Special Education Diploma compared to the students in general education who did not study academic courses related to disability issues. The table (1) shows the mean ratios and standard deviation which is obtained by each phrase in the questionnaire for those who have studied the academic course and those who have not studied this course yet.

Table 1. Ratios mean and standard deviation

\begin{tabular}{|c|c|c|c|c|c|}
\hline \multirow{2}{*}{ Phrase } & \multicolumn{2}{|c|}{ After studying the course } & \multicolumn{2}{|l|}{$\begin{array}{l}\text { Before } \\
\text { course }\end{array}$} & \multirow{2}{*}{$\begin{array}{l}\text { Significance } \\
\text { level }\end{array}$} \\
\hline & Deviation & Average & Deviation & Average & \\
\hline $\begin{array}{l}\text { 1-The inclusion of children with special } \\
\text { needs is appropriate educationally action. }\end{array}$ & 0.617419 & 3.541667 & 0.601417 & 3.25 & \\
\hline $\begin{array}{l}\text { 2-The inclusion of children with special } \\
\text { needs with their normal peers benefited } \\
\text { them in the behavioral aspects. }\end{array}$ & 0.683843 & 3.520833 & 0.757937 & 3.25 & \\
\hline $\begin{array}{l}\text { 3- The inclusion of children with special } \\
\text { needs with their normal peers give them } \\
\text { many social skills. }\end{array}$ & 0.741082 & 3.5625 & 0.651988 & 3.479167 & \\
\hline $\begin{array}{l}\text { 4. The right place for educating the } \\
\text { children with special needs in pre-school } \\
\text { age is the normal class in kindergarten or } \\
\text { nursery. }\end{array}$ & 0.963887 & 2.916667 & 1.051004 & 2.458333 & \\
\hline $\begin{array}{l}\text { The inclusion of children with special } \\
\text { needs with their normal peers to develop } \\
\text { their cognitive and academic abilities. }\end{array}$ & 0.651988 & 3.520833 & 0.856504 & 3.229167 & \\
\hline $\begin{array}{l}\text { 6-. The inclusion of children with special } \\
\text { needs at an early stage contributes in } \\
\text { accepting their normal peers for them. }\end{array}$ & 0.681246 & 3.5625 & 0.74347 & 3.520833 & \\
\hline $\begin{array}{l}\text { 7- It is preferable to children with special } \\
\text { needs to learn in an educational } \\
\text { environment in which the programs of } \\
\text { inclusion are applied. }\end{array}$ & 0.569621 & 3.625 & 0.713348 & 3.458333 & \\
\hline $\begin{array}{l}\text { 8- The inclusion is appropriate to the } \\
\text { characteristics of children with simple } \\
\text { disabilities. }\end{array}$ & 0.581939 & 3.708333 & 0.74347 & 3.479167 & \\
\hline $\begin{array}{l}\text { 9- The children with simple disabilities } \\
\text { have the right to receive their education } \\
\text { in regular classrooms in which the } \\
\text { requirements of inclusion programs are }\end{array}$ & 0.569621 & 3.625 & 0.551834 & 3.6875 & \\
\hline
\end{tabular}


available.

10. It is better to include visual- impaired children and who can read printed educational materials in the regular classrooms.

$\begin{array}{llll}1.174304 & 2.9375 & 1.120212 & 2.354167\end{array}$

11. It is preferable to include the visualimpaired children and who cannot read printed educational materials in the $\begin{array}{llll}1.12041 & 1.25 & 0.944375 & 1.041667\end{array}$ regular classrooms.

12. It is better to include the haring impaired children - hearing impairment and who do not suffer from full deafness in the regular classrooms.

13. It is not preferable to include the children who suffer from full deafness in the regular classrooms.

14. It is better to include motor- impaired children in the regular classrooms.

\section{$\begin{array}{llll}1.184826 & 2.854167 & 1.078481 & 2.666667\end{array}$}

$\begin{array}{llll}1.308557 & 2.895833 & 1.287556 & 2.958333\end{array}$

$\begin{array}{lllll}0.820828 & 3.416667 & 1.046566 & 2.395833 & .000 * *\end{array}$

15. It is preferable to include the children who suffer from cerebral palsy in the regular classrooms.

16. It is better to include children with speech and language disorders in the regular classrooms.

17- It is better to include children who suffer from epilepsy in the regular classrooms.

18. It is preferable to include children who suffer from chronic diseases in the regular classrooms.

19. It is preferable to include children who suffer from emotional and behavioral disorders in the regular classrooms.

20. It is not preferable to include children who suffer from severe autism in the regular classrooms.

21. It is preferable to include children who suffer from learning difficulties in the regular classrooms.

22. Inclusion Programs in need to intensive training for ordinary teachers.

23. It is Preferable to give the children with special needs every possible opportunity to interact and participate in the regular classroom.

24. The presence of children with special needs in the regular classroom leads to some problems.

$\begin{array}{llll}0.412031 & 3.854167 & 0.649263 & 3.5625\end{array}$

$\begin{array}{lllll}0.890255 & 2.875 & 1.193956 & 1.75 & .000^{* *} \\ 1.136125 & 3.166667 & 1.458042 & 2.791667 & \\ 0.581939 & 3.708333 & 1.020838 & 3.020833 & .001 * * \\ 0.412031 & 3.854167 & 0.649263 & 3.5625 & \\ & & & & \\ 0.605823 & 3.625 & 0.449093 & 3.729167 & \\ & & & & \end{array}$


25. The presence of children with special needs in the regular classrooms encourages the normal children to accept $\begin{array}{llll}0.618495 & 3.479167 & 0.833688 & 3.166667\end{array}$ them.

26. Children Programs of inclusion enable children with special needs to make normal friends.

$\begin{array}{llll}0.530957 & 3.625 & 0.57735 & 3.416667\end{array}$

27. Children Programs of inclusion enable children with special needs to imitate the behavioral patterns of the normal child.

$\begin{array}{llll}0.907025 & 3.333333 & 0.757937 & 3.25\end{array}$

28. Children with special needs effectively participate in school and educational activities with their ordinary colleagues.

29. Children with special needs who are studying in inclusion schools get their educational needs more than children with special needs who are studying in special education centers.

30. The teachers working in inclusion schools must have high training enable them to deal with children with special needs.

31. The ordinary children accept the children with special needs with them in the regular school when the necessary awareness programs are available.

32. Teachers working with children with special needs must enjoy with positive trends towards inclusion programs.

33. The regular schools must modify their programs to suit children with special needs.

34. Inclusion Programs provide equality and equal opportunities for ordinary children and children with special needs.

35. Inclusion in all its forms is one of the rights of children with special needs.

0.50

$\begin{array}{llll}0.818394 & 3.270833 & 0.67602 & 3.270833\end{array}$

$\begin{array}{llll}1.237705 & 2.5 & 1.187815 & 2.3125\end{array}$

$\begin{array}{llll}0.53924 & 3.583333 & 0.643778 & 3.395833\end{array}$

$\begin{array}{llll}0.53924 & 3.583333 & 0.643778 & 3.395833\end{array}$

$\begin{array}{llll}0.476393 & 3.833333 & 0.511828 & 3.6875\end{array}$

$\begin{array}{llll}0.472187 & 3.770833 & 0.771558 & 3.479167\end{array}$

$\begin{array}{llll}0.85883 & 3.333333 & 0.785507 & 3.25\end{array}$

36. The inclusion of children with special needs has an economic benefit in terms of low cost.

$\begin{array}{llll}0.503534 & 3.708333 & 0.652328 & 3.5\end{array}$

37. Positive trends for those in charge of inclusion programs towards inclusion is one of the conditions for success in its application.

38. Inclusion programs have some benefits for families with special needs.

39. The ordinary Teacher takes advantage of the application of inclusion programs

$\begin{array}{llll}1.009705 & 3.458333 & 1.030561 & 3.041667 \\ 0.643778 & 3.604167 & 0.617419 & 3.458333 \\ 0.503534 & 3.708333 & 0.57735 & 3.583333\end{array}$


40. People with moderate and severe disabilities can be included socially and recreational.

$\begin{array}{lllll}0.898926 & 3.145833 & 0.757644 & 3.354167 & .005^{* *}\end{array}$

41. The laws and legislations must be amended to confirm the right of people with special needs in inclusion.

$\begin{array}{llll}0.945313 & 3 & 1.101257 & 2.25\end{array}$

42. The preparation of the ordinary teacher and the teacher of special education during their university education is essential to the success of inclusion programs.

43-The preparation of ordinary students to accept the students with special needs is essential to the success of inclusion programs.

44-The amendment of the engineering environment of school is necessary for inclusion programs.

45-The existence of Resource Room in the ordinary school is essential to the success of inclusion programs.

$\begin{array}{llll}0.609834 & 3.604167 & 0.706793 & 3.395833\end{array}$

General average
0.483779
3.75
0.769256
3.5625

$\begin{array}{llll}0.429415 & 3.833333 & 0.45934 & 3.791667\end{array}$

$\begin{array}{llll}0.630209 & 3.666667 & 0.743768 & 3.5\end{array}$

0.519137

$3.833333 \quad 0.54415$

3.708333

\section{Discussion of the Study Results}

Through the above table which shows the opinion of both samples in the questionnaire questions, it can observe the following:

1- There are statistically significant differences in favor of students who have studied the academic education course of children with special needs in the ordinary schools towards the inclusion of disabled children with normal ones in the ordinary schools. This emphasizes the general objective of the study; knowing the individual differences between the two levels. Also, it stresses the importance of training during teaching students to change their negative attitudes towards disability issues.

2- There are statically significant differences for a number of phrases in favor of the fifth level students. It also emphasizes the positivism of students' attitude to include the fourth level disabled students. (The phrases, 14, $19.21,40)$ are among these ones. Through review of these phrases, it is noted that the phrase number (14) talks about the preference of including children with motor impairment in the regular classrooms, while fifth level students emphasized the importance of inclusion with arithmetic average of more than 3.5 , the fourth level students had an opinion that is not negative, but less positive as the arithmetic average was less than 2.5. This is confirmed by the role of the academic course in modifying the direction of the fifth level students compared with the fourth level.

This is reflected in the phrase number (19) that talk about (It is preferable to include the children who suffer from behavioral and emotional disorders in the regular classes), where there are differences of statistical significance the fifth level students with a high mathematical average compared with the fourth level students. This is confirmed by the extent of the fifth level students understanding of the importance of including students with behavioral and emotional disorders. These students are originally in regular classes, except for some groups that are in need to hospitals and treatment centers.

Also, differences of significance are shown in the phrase number (21) as it talks about (It is preferable to include the children who suffer from learning difficulties in the regular classrooms). While the fifth level students approved on the importance of existing the students with learning difficulties in the ordinary classroom, the students of the fourth level approved with a mathematical average less than the fifth level.

Also, differences of statistical significance between the two levels in favor of the students of the fifth level in the 
phrase number (40) as it talks about (It is possible to include the children with moderate and severe disabilities socially and recreational). The students of the fifth level approved with a high average compared with the students of the fourth level. Through the above observations, we find that the academic course of education for children with special needs plays a major role in modifying the trends in favor of the students of the fifth level, where all the phrases in which significant differences are found are explained and defined in the book. The students of the fifth level benefited in defining the categories suitable for the full inclusion and the categories suitable for the social inclusion. Their attitudes were logical and consistent with the objectives of the course while the fourth level students could not modify their attitudes with the same rate of positivism of the fifth level students.

3- Through the review of the results of the study, it is noted that the attitude of the students in both the fifth level and fourth level is positive towards the inclusion of disabled children, but there are significant differences in favor of the fifth level students.

4- Through the results of the study it is noted that the mathematical average height in favor of both samples with an average more than 3.5 and this confirms positivism towards both samples.

5- It is noted through all the phrases that deal with the issues of disability in general and the issues, conditions and the factors of succeeding inclusion, there was consensus among the students at the fifth and fourth level students.

6- The researcher noticed the absence of statistically significant differences in favor of the fourth level students compared with the fifth level students in any one of the phrases in the study. This confirms the importance of education course for children with special needs in modifying the attitudes of students towards inclusion.

7- It is noted an agreement between the opinions of both samples in many of the phrases, either an agreement with high average such as the phrases number $(3.9,25,28.30,37,39.42,43,44.45)$, which discuss general trends and needs or semi- agreement among many who work or have relations with the fields of special education. For example, the phrase "The laws and legislations must amended to affirm the right of students with special needs in inclusion", the phrase" the preparation of the ordinary teacher and the teacher of special education during their university education is essential to the success of inclusion programs", the phrase" modifying the engineering environment of school is necessary for applying the inclusion programs", the phrase" the existence of sources room in the regular school is essential to the success of inclusion programs and other phrases that emphasize general principles.

8- It is noted an agreement between the opinions of both samples. Also, consensus in getting some phrases on weak averages or negative trends, either for the students at the fifth level or students at the fourth level, such as the phrases $(11,15)$. The phrase (11) says "It is preferable to include the children who suffer from visual impairment and cannot read printed educational materials in the regular classrooms." The opinions of both samples were negative towards the children who suffer from visual impairment and cannot read printed educational materials. Also, there is an agreement in the phrase (15), which says "It is preferable to include the children who suffer from cerebral palsy in the regular classes". The opinions of both samples were negative with an arithmetic average of less than one degree.

\subsection{Recommendations of the Study}

The researcher recommends with the following:

1- Working on the modification and development of the academic courses for students of special education departments to modify their attitudes towards the issues of including disabled students.

2- Increasing the number of workshops and training courses for student teachers to increase their positive trend towards including the disabled students in particular and the issues of disability in general.

3- Working to create some academic educational courses such as Introduction to Special Education for students of colleges of education departments away from the Department of Special Education to increase and modify their attitudes towards inclusion programs.

4- Expansion in the field research that work to modify the trends toward inclusion, either for parents, teachers, managers or other categories of society.

5- What is clearly important is that pre-service teacher training must consider the attitudes, beliefs and concerns of teachers in training and ensure that their courses provide the most appropriate preparation to better enable them to be prepared for inclusive education. This study has focused on the attitudes of pre-service teachers prior to their involvement in university training on inclusive education. In future studies, we will report how 
participation in a university program on special education impacted on these participants' attitudes, concerns and comfort levels

\section{References}

Abduljabbar, A. (1999). A study of the factorial honesty of the scale of attitudes towards including the disabled children and some variables relevant with these attitudes. Journal of King Saud University, Educational Sciences and Islamic Studies, 11(2), 73-99.

Abu, A. T., \& Mohammed, A. (2008). The effect of the professional diploma program in special education on the attitudes of teachers towards including the students with special needs. Department of Mental Health, the faculty of education, Fayoum University.

Kafafi, A. (2004). A Study of the attitudes toward the experience of including the children with special needs with the ordinary children in the primary school. Higher Advisory Committee for the development of special education programs.

Carroll, A., Forlin, C., \& Jobling, A. (2003). The impact of teacher training in special education on the attitudes of Australian preservice general educators towards people with disabilities. Teacher Education Quaterly, 30, 65-79.

Forlin, C., Jobling, A., \& Carroll, A. (2001). Preservice teachers' discomfort levels toward people with disabilities. The Journal of International Special Needs Education, 4, 32-38.

Forlin,C., Tait, K., Carroll, A., \& Jobling, A. (1999). Teacher education for diversity. Queensland Journal of Educational Research, 5.

Fred M. Al-Khatib. (2004). Identifying the attitudes of working cadres in the primary schools towards including the simple mentally disabled children. In the ordinary Schools in the Kingdom of Bahrain.

Larrivee, B. (1981). Effective of inservice training intensity on teachers attitudes toward mainstreaming. Exceptional Children, 48, 34-39.

Martin, E. W. (1974). Somethought on mainstreaming. Exceptional Children, 41, 150-153.

McDougall, J., Dewit, D. J., King, G., Mille, L., \& Steve (2004). High school-Aged Youth. Attitudes toward their peers with Disabilities: The role of school and student interpersonal Factors. International Journal of Disability, Development \& Education, 51(3), 287-314. http://dx.doi.org/10.1080/1034912042000259242

Ministry of Education, Kingdom of Saudi Arabia. (1429-1430). The General administration of Special Education, census. AH. Ministry's website on the internet.

Sharma, U., Ee, J., \& Desai, I. (2003). A comparison of Australian and Singaporeanpreservice teachers' attitudes and concerns about inclusive education. Teaching and Learning, 24(2), 207-217.

Sharma U., \& Forlin, C (2006). Earle pre-service teachers, Attitudes, Concerns and Sentiments about inclusive education: An international comparison of novice pre- service teachers. International Journal of Special Education, 21(2).

UNESCO. (1994). The Salamanca Statement and Framework for Action. Paper presented at the World Conference on Special Needs Education: Access and Quality, Salamanca, Spain.

Zeidan Ahmed Sartawi. (2005). The attitudes of teachers and students towards the inclusion of disabled children in the regular classrooms. Ministry's website on the internet. 